\title{
Impact of Different Treatment Concepts on Regional Failure in Advanced Oropharyngeal Cancer
}

\author{
STEPHAN HOCH ${ }^{1}$, KATHARINA THELEN $^{1}$, HILKE VORWERK ${ }^{2}$, CHRISTOPH NETZER ${ }^{1}$, \\ THOMAS WILHELM ${ }^{3}$, THOMAS GÜNZEL ${ }^{4}$ and AFSHIN TEYMOORTASH ${ }^{1}$ \\ ${ }^{1}$ Department of Otolaryngology, Head and Neck Surgery, Philipps University of Marburg, Marburg, Germany; \\ ${ }^{2}$ Department of Radiotherapy and Radiooncology, Philipps University of Marburg, Marburg, Germany; \\ ${ }^{3}$ Department of Otolaryngology, Head/Neck \& Facial Plastic Surgery, \\ Sana Kliniken Leipziger Land, Borna, Germany; \\ ${ }^{4}$ Department of Otolaryngology, Head and Neck Surgery, Borromäus Hospital, Leer, Germany
}

\begin{abstract}
Background: The management of patients with advanced oropharyngeal cancer is complex and mostly requires a multidisciplinary treatment approach. In general, organ preservation by primary concurrent radiochemotherapy (RCT), or surgery completed by adjuvant radiotherapy are established treatment strategies for these patients. However, it is unclear if primary treatment has an effect on regional tumor control. The purpose of the present study was to evaluate the regional control after different treatment concepts. Patients and Methods: Clinical data, including histological and radiological results, of 82 patients with T2-T3 oropharyngeal cancer and $N 2$ neck were retrospectively analyzed. They underwent either RCT with salvage neck dissection (ND) $(n=45)$, or primary transoral surgery with $N D$ and adjuvant $R C T(n=37)$. In all cases, the primary tumor was successfully treated, without evidence of local failure in the follow-up. Results: Overall, 11 (13.4\%) patients developed regional failure during the follow-up. There were no significant differences in frequency of regional failure $(p=0.75)$, distant metastasis $(p=0.35)$ and overall survival $(p=0.22)$ between treatment groups. However, 5-year diseasefree survival was significantly worse $(39.0 \%$ vs. $57.0 \%)$ for patients treated by $R C T$, with more frequent regional failure detected compared to surgically-treated patients in univariate analysis ( $p=0.04)$. Conclusion: Treatment concept does not seem to affect regional tumor control in advanced oropharyngeal cancer after successful treatment of the primary tumor.
\end{abstract}

Correspondence to: Stephan Hoch, MD, Department of Otolaryngology, Head and Neck Surgery, Philipps-University, Baldingerstrasse, 35043 Marburg, Germany. Tel: +49 064215866478, Fax: +49 064215866367, e-mail: hochs@med.uni-marburg.de

Key Words: Regional failure, oropharyngeal cancer, transoral surgery, radiochemotherapy.
Oropharyngeal squamous cell cancer (OSCC) accounts for about $2.8 \%$ of all cancer cases with a worldwide incidence estimated to be approximately 136,000 (1). Despite declining rates of tobacco use in Western countries, relative and absolute incidences of oropharyngeal cancer are increasing, especially among younger people. Thus, in the United States, the proportion of OSCC out of all patients with head and neck cancer has risen from $20 \%$ in the 1980 s to about $70 \%$ at the present, due to an altered risk profile (2). Whereas in former days, tobacco use was the main risk factor for the development of OSCC, nowadays there is an increasing incidence of OSCC cases associated with human papilloma virus (HPV) infection (2). Patients with HPV-associated tumors are characterized by a younger median age, small primary tumors, and more advanced nodal stage, as well as lower risk for secondary primaries (2-6). Furthermore overall response to treatment and overall survival are better than in HPV-negative OSCC (7).

Treatment of oropharyngeal cancer is complex and often requires an interdisciplinary approach. Treatment options include both organ-preserving and surgical treatment modalities. However, there is a lack of evidence regarding the oncological outcomes for the different treatment options. According to the literature, the oncological results appear to be similar and the choice of primary treatment concept is mainly historically influenced (8). Especially in the case of advanced tumor stage with cervical metastasis, the choice of primary treatment is a matter of controversial debate. In contrast to small tumors (T1-T2), which are usually treated surgically, locally advanced and functionally unresectable tumors (T4) are mostly treated with concurrent radiochemotherapy (RCT) and salvage surgery, if necessary. However, particularly in OSCC with T2-T3 primary tumors and advanced regional metastasis (N2), both treatment strategies are effective and the decision for each treatment approach may be discussed controversially. 
Since the development of regional failure is a common reason for treatment failure, especially in patients with advanced nodal stage (N2-N3) disease (9), it must be considered in the decision-making for each treatment concept. Different clinicopathological risk factors for regional failure in OSCC have been identified. Beside clinical characteristics such as smoking history and T- and $\mathrm{N}$-stage, histological characteristics, including HPV status and the presence of extranodal spread, local lymph vessel invasion, as well as residual disease at the primary site and nodal response to treatment, are associated with regional failure $(10,11)$.

Currently there is no level-one evidence which emphasizes the differences in oncological outcome, such as locoregional failure between transoral $\mathrm{CO}_{2}$-laser surgery (TLS) with adjuvant treatment and primary RCT with or without salvage surgery $(8,12)$. Facing these facts, the aim of the present study was to evaluate the regional tumor control, and overall and disease-free survival depending on the choice of the primary treatment concept in a homogeneous group of patients with T2-T3 N2 M0 OSCC [American Joint Committee on Cancer (AJCC) stage IVa] and successfully treatment of the primary tumor.

\section{Patients and Methods}

Clinical data and inclusion criteria. The clinical and histological data of patients with advanced OSCC who underwent either primary RCT with uni- or bilateral salvage neck dissection (ND) or combined TLS with adjuvant radiotherapy were retrospectively analyzed. Only patients with T2-3 squamous cell carcinoma, N2 neck, as well as radiologically and histologically proven complete response of the primary tumor were included. Exclusion criteria were local recurrence, metachronous secondary primary, distant metastases, or previous radiation therapy to the head and neck area, as well as a non-scheduled radiotherapy. Furthermore, patients with a follow-up of less than 1 year, except in the case of deathwere excluded from the study.

Altogether 82 patients (13 females and 69 males, median age at diagnosis 59.6 years, range $=36$ to 91 years) fulfilled the inclusion criteria. The clinical data of all patients, including tumor localization, tumor stage, HPV status, comorbidities, American Society of Anesthesiologists (ASA) classification, the development of regional recurrence and distant metastasis are summarized in Tables I and II.

Comorbidities. Pre-existing comorbidities were evaluated according to the documented data in the patient records by using the Charlson Comorbidity Index (CCI) (13). Defined scores were assigned to each comorbidity according to its severity. The CCI score of a patient was finally calculated by adding the scores for all comorbidities. The CCI score was then classified into three categories. These categories were mild (score 1-2), moderate (score $3-4$ ), and severe comorbidities (score $>4$ ). In addition, the physical status considering the comorbidities of each patient was preoperatively assessed by using the ASA classification which is a common method for the assessment of the physical status and the perioperative risk of the patients.

Treatment modalities. Altogether 45 (54.9\%) patients, underwent an organ-preserving treatment regimen consisting of primary RCT. Radiotherapy was carried out in all cases 5 days a week, with a mean radiation dose of $71.3 \mathrm{~Gy}$ (range $=65$ to $72 \mathrm{~Gy}$ ). In the first 3 weeks, radiotherapy was applied by 2 -Gy fractions per day, followed by $2 \times 1.4-G y$ fractions per day in the subsequent 3 weeks. Simultaneous chemotherapy was applied for 42 out of 45 patients and consisted of 5-fluorouracil (5-FU) as continuous infusion at $600 \mathrm{mg} / \mathrm{m}^{2} / 24 \mathrm{~h}$ during days $1-5$ and mitomycin $\mathrm{C}$ given at $10 \mathrm{mg} / \mathrm{m}^{2}$ on day 5 and day $36(n=21)$ or six cycles of cisplatin $\left(30 \mathrm{mg} / \mathrm{m}^{2}\right)$ weekly $(\mathrm{n}=18)$. Three patients received cetuximab instead of $5-\mathrm{FU}$ at $400 \mathrm{mg} / \mathrm{m}^{2}$ on day 7 before the start of radiotherapy followed by weekly doses of $250 \mathrm{mg} / \mathrm{m}^{2}$ during the 6 weeks of radiotherapy. A total of 23 out of the $45(51.1 \%)$ patients underwent salvage ND 10 to 12 weeks after the end of RCT. Salvage ND was carried out in cases of radiological evidence of residual lymph node metastases either uni- $(n=14)$ or bilaterally $(n=9)$. Altogether, 17 modified radical $N D$ and 15 selective ND were performed according to the extent of radiologically proven residual neck disease.

The remaining $37(45.1 \%)$ patients underwent a combined surgical approach with adjuvant RCT. The primary tumor was treated in all cases by TLS. In all cases, simultaneous ND was performed either uni- $(n=19 ; 51.4 \%)$ or bilaterally $(n=18 ; 48.6 \%)$. Different types of ND were performed according to the extent of radiologically proven neck disease. In most cases, modified radical ND $(n=33)$ was carried out. All patients underwent adjuvant radiotherapy for 5 days a week, with a mean radiation dose of 59.9 Gy (range $=41.4$ to $70.2 \mathrm{~Gy}$ ). In 27 patients a simultaneous chemotherapy with 5-FU and cisplatin was carried out.

Follow-up. Follow-up examination consisted of clinical inspection and palpation of the upper aerodigestive tract, as well as assessment of the neck lymph nodes bilaterally by ultrasound. During the first 2 years after diagnosis, the neck was examined at 4 - to 8 -week intervals, during the third year post diagnosis every 3 months, during the fourth year every 6 months, and from the fifth year onwards every 12 months. The average follow-up period was 4.1 years (range $=0.8$ to 11 years) for the whole patient group. In patients with suspicion for locoregional recurrence or a secondary tumor, further diagnostic procedures, including fine-needle aspiration cytology of suspicious neck nodes, pan-endoscopy and computed tomographic scan of the neck were conducted.

Statistical analysis. Clinical and histological characteristics of the study patients were evaluated by descriptive analysis. The analyzed clinical characteristics included age, sex, $\mathrm{N}$ classification, comorbidities, ASA classification and the development of regional recurrence, as well as distant metastases in the follow-up period, the treatment concept and radiation dose. The analyzed histological characteristics were tumor differentiation and the HPV status.

Chi-square test, Fisher's exact test or Wilcoxon-Mann-Whitney test were used to detect differences in the clinical and histological characteristics between both treatment groups. For nominal variables, differences between age groups were determined by a Chi-square test or Fisher's exact test. Group differences for continuous variables were tested with a Wilcoxon-Mann-Whitney test. Survival rates were calculated by using the Kaplan-Meier 
Table I. Patients and treatment characteristics $(n=82)$.

\begin{tabular}{lc}
\hline Characteristic & No. of patients $(\%)$ \\
\hline Gender & \\
Male & $69(84.1)$ \\
Female & $13(15.9)$ \\
Median age (range), years & $59.6(36-91)$ \\
Primary site & \\
Soft palate & $7(8.5)$ \\
Tonsil & $44(53.7)$ \\
Base of the tongue & $26(31.7)$ \\
Posterior pharyngeal wall & $5(6.1)$ \\
T-Classification & $52(63.4)$ \\
T2 & $30(36.6)$ \\
T3 & $7(8.5)$ \\
N-Classification & $52(63.4)$ \\
N2a & $23(28.1)$ \\
N2b & $1(1.2)$ \\
N2c & $51(62.2)$ \\
Differentiation of tumors & $30(36.6)$ \\
Well (G1) & \\
Moderate (G2) & $40(48.8)$ \\
Poorly (G3) & $42(51.2)$ \\
HPV status & $11(13.4)$ \\
Yes & $71(86.6)$ \\
No/ unknown & \\
Regional recurrence & $23(28.1)$ \\
Yes & $59(71.9)$ \\
No & \\
Distant metastasis & \\
Yes & \\
No & \\
\hline &
\end{tabular}

HPV: Human papilloma virus.

method with regard to the time period from the first to the last consultation or death. Differences between survival curves were evaluated by using the log-rank test. A $p$-value of 0.05 or less was considered significant.

\section{Results}

Clinical and histopathological characteristics. Both treatment groups were similar regarding age $(p=0.55)$, sex $(p=0.82), \mathrm{N}$ classification $(p=0.19)$, tumor differentiation $(p=0.80)$, ASA classification $(p=0.08)$ and comorbidities $(p=0.84)$. Only the HPV status and the mean radiation dose significantly differed, with more HPV-associated tumors $[\mathrm{n}=27(60.0 \%)$ vs. 13 (35.1\%), $p=0.04]$ and higher mean radiation dose (71.3 vs. $59.9 \mathrm{~Gy}, p<0.01)$ in the RCT group (Table II).

Regional failure and distant metastasis. A total of 11 (13.4\%) patients developed a unilateral regional recurrence in the followup period. These recurrences were detected more frequently in patients who underwent primary RCT than in patients with primary surgical approach $[\mathrm{n}=7(15.6 \%)$ vs. 4 (10.8\%)].
Table II. Univariate analysis of differences in clinical and histological characteristics between treatment groups.

\begin{tabular}{|c|c|c|c|}
\hline \multirow[b]{2}{*}{ Characteristic } & \multicolumn{2}{|c|}{ No. of patients (\%) } & \multirow[b]{2}{*}{$p$-Value* } \\
\hline & TLS $(\mathrm{n}=37)$ & $\mathrm{RCT}(\mathrm{n}=45)$ & \\
\hline \multicolumn{4}{|l|}{ Gender } \\
\hline Male & $32(86.5)$ & $37(82.2)$ & \\
\hline Female & $5(13.5)$ & $8(17.8)$ & 0.82 \\
\hline Median age (range), years & $61.0(36-82)$ & $57.0(36-91)$ & 0.55 \\
\hline \multicolumn{4}{|l|}{ ASA classification } \\
\hline I & $2(5.4)$ & $2(4.4)$ & \\
\hline II & $18(48.6)$ & $14(31.1)$ & \\
\hline III & $11(29.7)$ & $22(48.9)$ & \\
\hline Unknown & $6(16.2)$ & $7(15.6)$ & 0.08 \\
\hline \multicolumn{4}{|l|}{ CCIs score } \\
\hline 0 & $14(37.8)$ & $19(42.2)$ & \\
\hline 1 & $12(32.4)$ & $12(26.7)$ & \\
\hline 2 & $4(10.8)$ & $5(11.1)$ & \\
\hline 3 & $1(2.7)$ & $2(4.4)$ & \\
\hline Unknown & $6(16.2)$ & $7(15.6)$ & 0.84 \\
\hline \multicolumn{4}{|l|}{ Differentiation } \\
\hline Well (G1) & $0(0)$ & $1(2.2)$ & \\
\hline Moderate (G2) & $25(67.6)$ & $26(57.8)$ & \\
\hline Poorly (G3) & $12(32.4)$ & $18(40.0)$ & 0.80 \\
\hline \multicolumn{4}{|l|}{ HPV status } \\
\hline Positive & $13(35.1)$ & $27(60.0)$ & \\
\hline Negative & $19(51.4)$ & $13(28.9)$ & \\
\hline Unknown & $5(13.5)$ & $5(11.1)$ & 0.04 \\
\hline \multicolumn{4}{|l|}{ Mean radiation } \\
\hline \multicolumn{4}{|l|}{ N-Classification } \\
\hline $\mathrm{N} 2 \mathrm{a}$ & $3(8.1)$ & $4(8.9)$ & \\
\hline $\mathrm{N} 2 \mathrm{~b}$ & $27(73.0)$ & $25(55.5)$ & \\
\hline $\mathrm{N} 2 \mathrm{c}$ & $7(18.9)$ & $16(35.6)$ & 0.19 \\
\hline \multicolumn{4}{|l|}{ Distant metastases } \\
\hline Yes & $8(21.6)$ & $15(33.3)$ & \\
\hline No & $29(78.4)$ & $30(66.7)$ & 0.35 \\
\hline \multicolumn{4}{|l|}{ Regional recurrence } \\
\hline Yes & $4(10.8)$ & $7(15.6)$ & \\
\hline No & $33(89.2)$ & $38(84.4)$ & 0.75 \\
\hline
\end{tabular}

HPV: Human papilloma virus, TLS: transoral laser surgery, RCT: radiochemotherapy, ASA: American Society of Anesthesiologists, CCI: Charlson Comorbidity Index.

Furthermore, patients treated with RCT more frequently developed distant metastasis $[\mathrm{n}=15(33.3 \%)$ vs. 8 (21.6\%)]. However, comparison of both treatment groups by univariate analysis showed no significant differences for the development of regional recurrence $(p=0.75)$ or distant metastasis $(p=0.35)$.

Survival analysis. The 5-year disease-free survival rates for the whole patient group, those treated with primary RCT, and those treated with TLS were $47.3 \%, 39.0 \%$ and $57.0 \%$, respectively. Survival analysis by Kaplan-Meier method revealed a significant difference for disease-free survival between treatment groups, with better results for surgically 
a

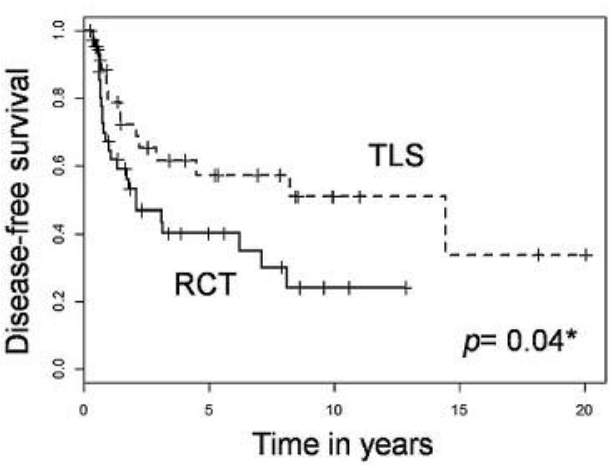

b

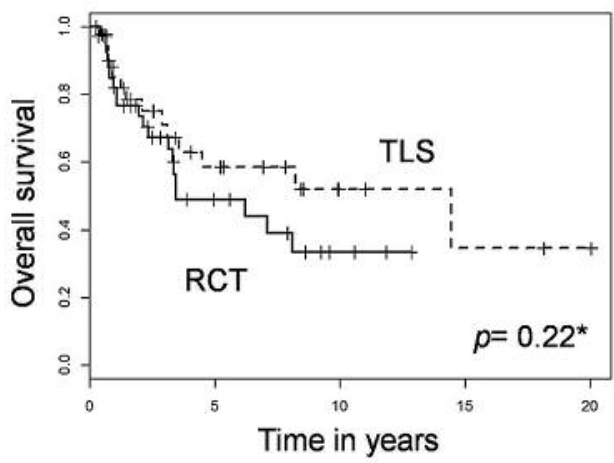

Figure 1. Kaplan-Meier curves for disease-free (a) and overall (b) survival after transoral laser surgery (TLS) or radiochemotherapy (RCT) for T2-3 N2 oropharyngeal cancer with local control. *Log-rank test.

treated patients $(p=0.04)$ (Figure 1a). Due to the significant difference in HPV status between treatment groups, a separate analysis for HPV-positive and negative patients was performed. This analysis showed a tendency of superiority for primarily surgically-treated patients, although no significant differences were found (Figure 2a).

The 5-year overall survival rates for the whole patient group, those treated with primary RCT, and those treated with TLS were $52.6 \%, 48.0 \%$ and $58.0 \%$ respectively. Comparing overall survival by the Kaplan-Meier analysis for all patients, as well as for HPV-positive and HPV-negative patients, no significant difference between the two treatment groups were detected (Figures $1 \mathrm{~b}$ and $2 \mathrm{~b}$ ). However, this analysis also showed a tendency for a better outcome of primarily surgically treated patients.

\section{Discussion}

The management of OSCC is evolving because of enhanced understanding of the oncogenic process, changes in diagnostic techniques, and developing combinations of therapy, both surgical and non-surgical (14). As recommended by the National Comprehensive Cancer Network Clinical Practice Guidelines in Oncology for Head and Neck Cancer, advanced OSCC requires multimodal treatment approaches consisting of either surgery with adjuvant irradiation, or concurrent RCT along with salvage surgery as necessary (15). In this context, it is well known that a combination of surgery and radiotherapy are superior to a single modality for controlling advanced cervical (N2 to N3) disease (16).

In the past, open surgical approaches comprised of en bloc resection of the tumor and neck dissection with free flap reconstruction of the pharynx. However, access to the oropharynx often included lip lysis, mandibular osteotomy and/or transhyoid approaches followed by pharyngectomy or glossectomy (17), which is associated with significant morbidity for the patients. Thus, nowadays minimally invasive surgical approaches such as TLS or transoral robotic surgery (TORS) have been developed as tumor-targeted surgical treatment procedures (18). In the present study, all patients with surgical treatment concept underwent TLS with simultaneous ND.

There are heterogeneous data from several previous studies indicating that the regional control rate in primary surgically-treated OSCC is about $90 \%$ or even higher. Thus, in a systematic review investigating the functional and oncological results of TORS for T1-T2 OSCC, the aggregate regional control rate was $91 \%$ (19). In another systematic review comparing TORS with intensity-modulated radiotherapy (IMRT) for T1-T2 OSCC, a 2-year regional control rate of $90-96 \%$ for TORS/TLS was found (20). Even in patients with advanced OSCC, similar results were described previously. Thus, in a multicenter clinical trial of 204 patients with stage III and IV OSCC who were treated by TLS only, seven $(3.4 \%)$ patients suffered from recurrence in the neck at a median interval of 10 months after treatment (21). Another study, evaluating TLS and adjuvant therapy for advanced-stage OSCC, recorded four (4.7\%) out of 84 patients as having a local recurrence (17). However, the data of previous studies were based on a relative inhomogeneous patient collective, including $\mathrm{T} 1$ and $\mathrm{T} 4$ primaries as well as lymph node metastasis classified from N0 to N3 at diagnosis. Compared to the literature, we found a slightly higher regional recurrence rate of $10.8 \%$ in the present study, which may be explained by the fact that all patients were suffering from advanced cervical metastasis (N2) at the time of diagnosis and the follow-up period was comparably long mean at 4.1 years in the present study. However, patients with local recurrence and metachronous second primary were 

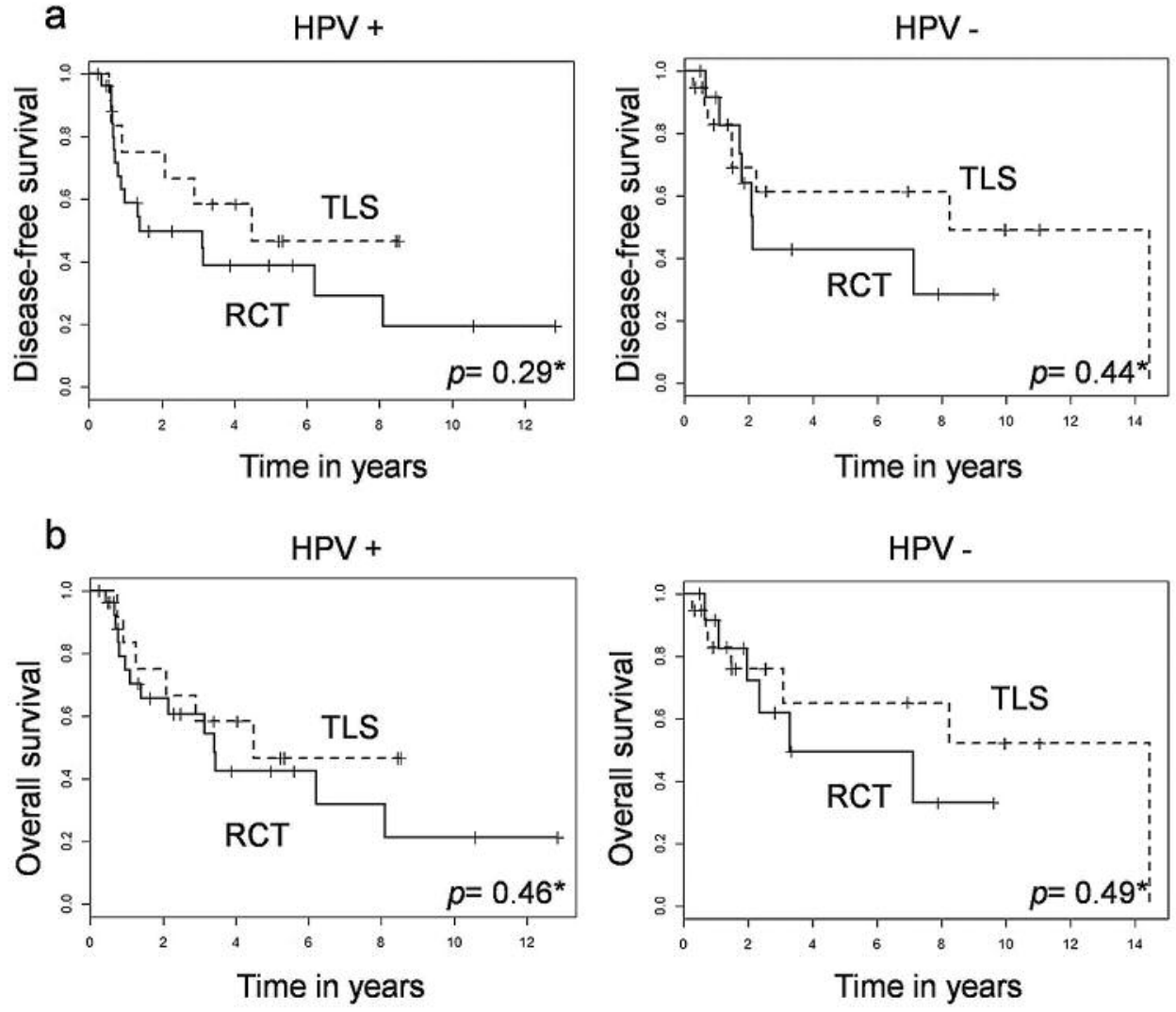

Figure 2. Kaplan-Meier curves for disease-free (a) and overall (b) survival according to human papilloma virus (HPV) status after transoral laser surgery (TLS) or radiochemotherapy (RCT) for T2-3 N2 oropharyngeal cancer with local control. *Log-rank test.

excluded from the present study. Thus, an even higher regional recurrence rate should be expected.

Considering overall survival after primary transoral surgery for OSCC, various data are reported in the literature. Mydlarz et al. in their review of oncological outcomes of transoral surgery for OSCC found 5-year overall survival rates of between 52 and $91 \%$ (22). Almeida et al. found a 2year overall survival rate of $82-94 \%$ in a TORS series compared to $84-96 \%$ for primary RCT (20). In a further multicenter clinical trial of 204 patients with stage III and IV OSCC who were treated by TLS, the overall survival rate after 5 years was $78 \%$ and disease-free survival was $74 \%$ (21). In another study, evaluating TLS and adjuvant therapy for advanced-stage OSCC in 84 patients, the 5-year overall survival rate was $88 \%$ (17). Thus, the comparatively low disease-free and overall survival rates of $57 \%$ and $58 \%$ in the present study may be explained by previous studies including inhomogeneous patient cohorts with various tumor stages. Organ-preserving treatment procedures in the form of concurrent RCT have been increasingly applied for patients with advanced OSCC (stage III, IVa and IVb) since the publication of the Intergroup trial in 2003 (23). Several studies confirmed the evidence that concomitant RCT is more effective than radiotherapy alone for patients with advanced OSCC $(24,25)$.

The response rates of the primary tumor seem to be superior compared to neck lymph node metastases in patients with primary RCT. Previous investigations revealed complete response rates of the primary tumor and neck metastases in up to $86 \%$ and $69 \%$, respectively (26). Hence the response of neck metastases depends on the size of the initial neck disease, with a decrease from about $80 \%$ for $\mathrm{N} 1$ necks to about $40 \%$ for N3 necks (27). In cases with complete cervical response, the cervical recurrence rate seems to be less than $5 \%$ regardless of performing salvage ND $(28,29)$. Irrespective of the initial cervical response, subsequent neck failure after RCT and salvage surgery, even in patients with advanced regional disease at presentation (N2), seems to be a rare condition, developing in about 5\% of all cases (30-32). In previous studies of inhomogeneous groups of patients with RCT for OSCC, various regional control rates were reported. These varied between $97 \%$ after 
2 years $(20), 94 \%$ after 3 years $(33,34)$ and $90 \%$ for N2b$2 \mathrm{c}$ necks 5 years after initial diagnosis (35). Compared to the literature, in the present study, we found a slightly worse regional control rate of $84.4 \%$ for patients with $\mathrm{N} 2 \mathrm{a}-\mathrm{c}$ neck.

Former studies evaluating RCT for advanced AJCC stage III and IV OSCC described 5-year overall survival as ranging from $22 \%$ to $74 \%$ (median=57\%) (17). The Meta-analysis of Chemotherapy in Head and Neck Cancer (MACH-NC) including 93 randomized trials with more than 17,000 patients revealed a 5-year overall survival rate of $33.7 \%$ for patients with advanced OSCC after primary RCT (24). In the present study, we found a 5-year overall survival rate of $48 \%$ after RCT, which is comparable to the current literature.

Currently, there is no level-one evidence for differences in oncological outcome between transoral surgery (TOS) with adjuvant treatment and primary RCT with or without salvage surgery $(8,12)$. A systematic review by Almeida et al. comparing TORS with IMRT for T1-T2 OSCC revealed no differences in survival outcomes between these treatment concepts in this group of patients (20).The Radiation Therapy Oncology Group (RTOG) 73-03 trial is the only randomized prospective study, comparing surgery versus radiation for advanced HNSCC. In this trial, no significant differences in overall survival were observed between the treatment groups. However, the study was based on data from the 1970s and OSCC comprised only a small subpopulation. Furthermore, the study has been criticized for being underpowered (36). However, in the present study, we found significantly better disease-free survival in a univariate analysis for patients with surgical treatment, which may be explained in part due to higher rate of regional recurrence and distant metastasis in the RCT group. Similar results were reported in a review by Hinni et al. who compared some former TOS series to prominent RCT trials, regarding the oncological outcome for HPV-positive OSCC (12). In this study the median locoregional recurrence rate was $5 \%$ (range $=0$ to $7 \%$ ) in the TOS series and $11 \%$ (range $=5$ to $13.6 \%$ ) in the RCT trials. Furthermore, they found a lower distant metastasis rate of $4.5 \%$ (range $=1.6$ to $6 \%$ ) in the TOS series compared to $6.5 \%$ (range $=5$ to $9 \%$ ) in the RCT trials. Additionally, the median overall survival rate was better after TOS $[92 \%$ (range $=81$ to $94 \%$ ) versus $89 \%$ (range $=82$ to $95 \%$ )].The reason for an increased distant metastasis rate among HPV-positive patients treated with RCT remains unclear. The authors of the above mentioned study pointed out that there may be a link to the early removal of the primary tumor in context of TOS. Presently, it has to be assumed that the results are approximately identical between the two treatment modalities. Prospective randomized trials, such as the recently opened ORATOR and EORTC1420-HNCG-ROG $(37,38)$, which compare surgical to non-surgical therapy in OSCC will hopefully give us further information about oncological differences between these two treatment concepts.
When discussing patterns of recurrence and distant failure, the influence of HPV status should be considered. P16Positive patients demonstrate an improved disease-free survival (21) and have a known tendency to develop late-onset distant failure $(39,40)$, although distant control rates seem to be similar between HPV-positive and HPV-negative OSCC at 70 to $90 \%$ (41). With respect to the relationship between regional recurrence and HPV status, there are inconsistent data in current literature. While some authors found no influence of HPV status on the regional control rate in patients primary treated by RCT (42), in another trial positive HPV status markedly reduced the risk for locoregional recurrence (43). Against this background and the fact that there were significant more patients with HPV-associated disease in the RCT group in the present study, we performed a separate analysis for HPV-positive and HPV-negative patients. However, the significant difference in disease-free survival was lost, although there was still a tendency for improved disease-free and overall survival in surgically treated patients. Potentially, this is a result of further confounders such as comorbidities and treatment-related morbidity and mortality. However, analyzing the comorbidities by $\mathrm{CCI}$ of the patients revealed no significant differences between the treatment groups. A statement about treatment-related morbidities cannot be made, as this was not the subject of the present study.

\section{Conclusion}

To our knowledge this is the first study to evaluate differences in regional failure between TLS and RCT in a homogeneous group of patients with T2-T3 N2 OSCC. Due to the retrospective setting of the study, there are some limitations, therefore the assessment of the clinical impact of these parameters on oncological results is limited. Analyzing the present data revealed no significant differences in regional recurrence between these two treatment approaches. However, there seems to be a tendency for better regional and distant control as well as disease-free survival in primary surgically treated patients. Large-scale prospective series are needed to confirm such a possibility.

\section{Conflicts of Interest}

None.

\section{Financial Disclosure}

No financial disclosures.

\section{References}

1 Siegel R, Naishadham D and Jemal A: Cancer statistics.CA Cancer J Clin 63(1): 11-30, 2013. 
2 Chaturvedi AK, Engels EA, Pfeiffer RM, Hernandez BY, Xiao W, Kim E, Jiang B, Goodman MT, Sibug-Saber M, Cozen W, Liu L, Lynch CF, Wentzensen N, Jordan RC, Altekruse S, Anderson WF, Rosenberg PS and Gillison ML: Human papillomavirus and rising oropharyngeal cancer incidence in the United States. J Clin Oncol 29(32): 4294-4301, 2011.

3 D'Souza G, Kreimer AR, Viscidi R, Pawlita M, Fakhry C, Koch WM, Westra WH and Gillison ML: Case-control study of human papillomavirus and oropharyngeal cancer. N Engl J Med 356(19): 1944-1956, 2007.

4 Huang SH, Perez-Ordonez B, Liu FF, Waldron J, Ringash J, Irish J, Cummings B, Siu LL, Kim J, Weinreb I, Hope A, Gullane P, Brown D, Shi W and O'Sullivan B: Atypical clinical behaviour of p16-confirmed HPV-related oropharyngeal squamous cell carcinoma treated with radical radiotherapy. Int J Radiat Oncol Biol Phys 82(1): 276-283, 2012.

5 Goldenberg D, Begum S, Westra WH, Khan Z, Sciubba J, Pai SI, Califano JA, Tufano RP and Koch WM: Cystic lymph node metastasis in patients with head and neck cancer: an HPVassociated phenomenon. Head Neck 30(7): 898-903, 2008.

6 Chu A, Genden E, Posner M and Sikora A: A patient-centered approach to counseling patients with head and neck cancer undergoing human papilloma virus testing: a clinician's guide. Oncologist 18(2): 180-189, 2013.

7 Cohen MA, Basha SR, Reichenbach DK, Robertson E and Sewell DA: Increased viral load correlates with improved survival in HPV-16-associated tonsil carcinoma patients. Acta Otolaryngol 128(5): 583-589, 2008.

8 Knecht R, Bussmann L, Möckelmann N and Lörincz BB: Is (chemo)radiotherapy really the future standard in the treatment of oropharyngeal carcinoma? HNO 64(4): 221-226, 2016.

9 Robbins KT, Ferlito A, Suárez C, Brizel DM, Bradley PJ, Pellitteri PK, Clayman GL, Kowalski LP, Genden EM and Rinaldo A: Is there a role for selective neck dissection after chemoradiation for head and neck cancer? J Am Coll Surg 199(6): 913-916, 2004

10 Vainshtein JM, Spector ME, McHugh JB, Wong KK, Walline HM, Byrd SA, Komarck CM, Ibrahim M, Stenmark MH, Prince ME, Bradford CR, Wolf GT, McLean S, Worden FP, Chepeha $\mathrm{DB}$, Carey $\mathrm{T}$ and Eisbruch A: Refining risk stratification for locoregional failure after chemoradiotherapy in human papillomavirus-associated oropharyngeal cancer. Oral Oncol 50(5): 513-519, 2014.

11 Li XM, Di B, Shang YD, Tao ZF, Cheng JM and He ZG: Value of postoperative radiation therapy for regional control after dissection in head and neck squamous cell carcinoma cases. Asian Pac J Cancer Prev 14(7): 4273-4278, 2013.

12 Hinni ML, Nagel $\mathrm{T}$ and Howard B: Oropharyngeal cancer treatment: the role of transoral surgery. Curr Opin Otolaryngol Head Neck Surg 23(2): 132-138, 2015

13 Charlson ME, Pompei P, Ales KL and MacKenzie CR: A new method of classifying prognostic comorbidity in longitudinal studies: development and validation. J Chronic Dis 40(5): 373383, 1987.

14 Cohan DM, Popat S, Kaplan SE, Rigual N, Loree T and Hicks WL Jr: Oropharyngeal cancer: current understanding and management. Curr Opin Otolaryngol Head Neck Surg 17(2): 8894, 2009.

15 Pfister DG, Spencer S, Brizel DM, Burtness B, Busse PM, Caudell JJ, Cmelak AJ, Colevas AD, Dunphy F, Eisele DW,
Foote RL, Gilbert J, Gillison ML, Haddad RI, Haughey BH, Hicks WL Jr, Hitchcock YJ, Jimeno A, Kies MS, Lydiatt WM, Maghami E, McCaffrey T, Mell LK, Mittal BB, Pinto HA, Ridge JA, Rodriguez CP, Samant S, Shah JP, Weber RS, Wolf GT, Worden F, Yom SS, McMillian N and Hughes M: National Comprehensive Cancer Network. Clinical practice guidelines in oncology. Head and neck cancers, Version 1.2015. Available at: https://www.nccn.org/professionals/physician_gls/f_guidelines.as p\#head-and-neck

16 Barkley HT Jr, Fletcher GH, Jesse RH and Lindberg RD: Management of cervical lymph node metastases in squamous cell carcinoma of the tonsillar fossa, base of tongue, supraglottic larynx, and hypopharynx. Am J Surg 124(4): 462-467, 1972.

17 Rich JT, Milov S, Lewis JS Jr., Thorstad WL, Adkins DR and Haughey BH: Transoral laser microsurgery (TLM) +/- adjuvant therapy for advanced stage oropharyngeal cancer: outcomes and prognostic factors. Laryngoscope 119(9): 1709-1719, 2009.

18 Lee SY, Park YM, Byeon HK, Choi EC and Kim SH: Comparison of oncologic and functional outcomes after transoral robotic lateral oropharyngectomy versus conventional surgery for T1 to T3 tonsillar cancer. Head Neck 36(8): 11381145, 2014.

19 Kelly K, Johnson-Obaseki S, Lumingu J and Corsten M: Oncologic, functional and surgical outcomes of primary transoral robotic surgery for early squamous cell cancer of the oropharynx: a systematic review. Oral Oncol 50(8): 696-703, 2014.

20 de Almeida JR, Byrd JK, Wu R, Stucken CL, Duvvuri U, Goldstein DP, Miles BA, Teng MS, Gupta V and Genden EM: A systematic review of transoral robotic surgery and radiotherapy for early oropharynx cancer: a systematic review. Laryngoscope 124(9): 2096-2102, 2014.

21 Haughey BH, Hinni ML, Salassa JR, Hayden RE, Grant DG, Rich JT, Milov S, Lewis JS Jr and Krishna M: Transoral laser microsurgery as primary treatment for advanced-stage oropharyngeal cancer: a United States multicenter study. Head Neck 33(12): 1683-1694, 2011.

22 Mydlarz WK, Chan JY and Richmon JD: The role of surgery for HPV-associated head and neck cancer. Oral Oncol 51(4): 305313, 2015.

23 Adelstein DJ, Li Y, Adams GL, Wagner H Jr, Kish JA, Ensley JF, Schuller DE and Forastiere AA: An intergroup phase III comparison of standard radiation therapy and two schedules of concurrent chemoradiotherapy in patients with unresectable squamous cell head and neck cancer. J Clin Oncol 21(1): 92-98, 2003.

24 Pignon JP, le Maître A, Maillard E, and Bourhis J; MACH-NC Collaborative Group: Meta-analysis of chemotherapy in head and neck cancer (MACH-NC): an update on 93 randomised trials and 17,346 patients. Radiother Oncol 92(1): 4-14, 2009.

25 Sharma A, Mohanti BK, Thakar A, Bahadur S and Bhasker S: Concomitant chemoradiation versus radical radiotherapy in advanced squamous cell carcinoma of oropharynx and nasopharynx using weekly cisplatin: a phase II randomized trial. Ann Oncol 21(11): 2272-2277, 2010.

26 Hanna E, Alexiou M, Morgan J, Badley J, Maddox AM, Penagaricano J, Fan CY, Breau R and Suen J: Intensive chemoradiotherapy as a primary treatment for organ preservation in patients with advanced cancer of the head and neck: efficacy, toxic effects, and limitations. Arch Otolaryngol Head Neck Surg 130(7): 861-867, 2004. 
27 Forest VI, Nguyen-Tan PF, Tabet JC, Olivier MJ, Larochelle D, Fortin B, Gélinas M, Soulières D, Charpentier D and Guertin L: Role of neck dissection following concurrent chemoradiation for advanced head and neck carcinoma. Head Neck 28(12): 1099$1105,2006$.

28 Wee JT, Anderson BO, Corry J, D'Cruz A, Soo KC, Qian CN, Chua DT, Hicks RJ, Goh CH, Khoo JB, Ong SC, Forastiere AA and Chan AT: Management of the neck after chemoradiotherapy for head and neck cancers in Asia: consensus statement from the Asian Oncology Summit 2009. Lancet Oncol 10(11): 1086-1092, 2009.

29 Johnson CR, Silverman LN, Clay LB and Schmidt-Ullrich R: Radiotherapeutic management of bulky cervical lymphadenopathy in squamous cell carcinoma of the head and neck: Is postradiotherapy neck dissection necessary? Radiat Oncol Investig 6(1): 52-57, 1998.

30 Robbins KT, Wong FSH, Kumar P, Hartsell WF, Vieira F, Mullins B and Niell HB: Efficacy of targeted chemoradiation and planned selective neck dissection to control bulky nodal disease in advanced head and neck cancer. Arch Otolaryngol Head Neck Surg 125(6): 670-675, 1999.

31 Stenson KM, Huo D, Blair E, Cohen EE, Argiris A, Haraf DJ and Vokes EE: Planned post-chemoradiation neck dissection: significance of radiation dose. Laryngoscope 116(1): 33-36, 2006.

32 Lango MN, Andrews GA, Ahmad S, Feigenberg S, Tuluc M, Gaughan J and Ridge JA: Postradiotherapy neck dissection for head and neck squamous cell carcinoma: pattern of pathologic residual carcinoma and prognosis. Head Neck 31(3): 328-337, 2009.

33 Setton J, Caria N, Romanyshyn J, Koutcher L, Wolden SL, Zelefsky MJ, Rowan N, Sherman EJ, Fury MG, Pfister DG, Wong RJ, Shah JP, Kraus DH, Shi W, Zhang Z, Schupak KD, Gelblum DY, Rao SD and Lee NY: Intensity-modulated radiotherapy in the treatment of oropharyngeal cancer: an update of the Memorial Sloan-Kettering Cancer Center experience. Int J Radiat Oncol Biol Phys 82(1): 291-298, 2012.

34 O'Sullivan B, Huang SH, Perez-Ordonez B, Massey C, Siu LL, Weinreb I, Hope A, Kim J, Bayley AJ, Cummings B, Ringash J, Dawson LA, Cho BC, Chen E, Irish J, Gilbert RW, Hui A, Liu FF, Zhao H, Waldron JN and Xu W: Outcomes of HPV-related oropharyngeal cancer patients treated by radiotherapy alone using altered fractionation. Radiother Oncol 103(1): 49-56, 2012.

35 Garden AS, Kies MS, Morrison WH, Weber RS, Frank SJ, Glisson BS, Gunn GB, Beadle BM, Ang KK, Rosenthal DI and Sturgis EM: Outcomes and patterns of care of patients with locally advanced oropharyngeal carcinoma treated in the early 21st century. Radiat Oncol 29;8: 21, 2013.

36 Kramer S, Gelber RD, Snow JB, Marcial VA, Lowry LD, Davis LW and Chandler R: Combined radiation therapy and surgery in the management of advanced head and neck cancer: final report of study 73-03 of the Radiation Therapy Oncology Group. Head Neck Surg 10(1): 19-30, 1987.
37 Nichols AC, Yoo J, Hammond JA, Fung K, Winquist E, Read N, Venkatesan V, MacNeil SD, Ernst DS, Kuruvilla S, Chen J, Corsten M, Odell M, Eapen L, Theurer J, Doyle PC, Wehrli B, Kwan K and Palma DA: Early-stage squamous cell carcinoma of the oropharynx: radiotherapy $v s$. trans-oral robotic surgery (ORATOR)--study protocol for a randomized phase II trial. BMC Cancer 13: 133, 2013.

38 EORTC 1420-HNCG-ROG "The best of" trial.http://www. eortc.org/research-groups/head-and-neckcancer-group/ongoingprojects/. [4479232; EORTC1420-HNGC-ROG]

39 Huang SH, Perez-Ordonez B, Weinreb I, Hope A, Massey C, Waldron JN, Kim J, Bayley AJ, Cummings B, Cho BC, Ringash J, Dawson LA, Siu LL, Chen E, Irish J, Gullane P, Hui A, Liu FF, Shen X, Xu W and O'Sullivan B: Natural course of distant metastases following radiotherapy or chemoradiotherapy in HPV-related oropharyngeal cancer. Oral Oncol 49(1): 79-85, 2013.

40 Trosman SJ, Koyfman SA, Ward MC, Al-Khudari S, Nwizu T, Greskovich JF, Lamarre ED, Scharpf J, Khan MJ, Lorenz RR, Adelstein DJ and Burkey BB: Effect of human papillomavirus on patterns of distant metastatic failure in oropharyngeal squamous cell carcinoma treated with chemoradiotherapy. JAMA Otolaryngol Head Neck Surg 141(5): 457-462, 2015.

41 Marur S and Burtness B: Oropharyngeal squamous cell carcinoma treatment: current standards and future directions. Curr Opin Oncol 26(3): 252-258, 2014.

42 Maquieira R, Haerle SK, Huber GF, Soltermann A, Haile SR, Stoeckli SJ and Broglie MA: No benefit for regional control and survival by planned neck dissection in primary irradiated oropharyngeal cancer irrespective of p16 expression. Eur Arch Otorhinolaryngol 273(7): 1841-1848, 2016.

43 Lohaus F, Linge A, Tinhofer I, Budach V, Gkika E, Stuschke M, Balermpas P, Rödel C, Avlar M, Grosu AL, Abdollahi A, Debus J, Bayer C, Belka C, Pigorsch S, Combs SE, Mönnich D, Zips D, von Neubeck C, Baretton GB, Löck S, Thames HD, Krause $M$ and Baumann M; DKTK-ROG: HPV16 DNA status is a strong prognosticator of loco-regional control after postoperative radiochemotherapy of locally advanced oropharyngeal carcinoma: results from a multicentre explorative study of the German Cancer Consortium Radiation Oncology Group (DKTKROG). Radiother Oncol 113(3): 317-23, 2014.

Received November 17, 2016

Revised December 16, 2016

Accepted December 20, 2016 